\title{
Demethylation effect of the antineoplaston AS2-1 on genes in colon cancer cells
}

\author{
MASATAKA USHIJIMA $^{1}$, YUTAKA OGATA ${ }^{2}$, HIDEAKI TSUDA ${ }^{3}$, \\ YOSHITO AKAGI $^{1}$, KEIKO MATONO ${ }^{1}$ and KAZUO SHIROUZU ${ }^{1}$
}

\author{
${ }^{1}$ Department of Surgery, Kurume University School of Medicine, Kurume 830-0011; ${ }^{2}$ Department of Surgery, \\ Kurume University Medical Center, Kurume 839-0863; ${ }^{3}$ Kurume Daiichi Social Insurance Hospital, Kurume 830-0013, Japan
}

Received August 20, 2013; Accepted September 25, 2013

DOI: $10.3892 /$ or.2013.2839

\begin{abstract}
Antineoplastons are naturally occurring peptides and amino acid derivatives found in human blood and urine. Antineoplastons have been shown to control neoplastic growth. In the present study, we investigated demethylation effect of the antineoplaston AS2-1 (a mixture of phenylacetylglutamine and phenylacetate in the ratio of $1: 4$ ) on various genes in colon cancer cells. An HpaII-MspI methylation microarray was used to investigate the methylation status of 51 genes at the promoter region in HCT116 and KM12SM human colon cancer cells before and after treatment of AS2-1. The expression of protein and mRNA of the demethylated genes by AS2-1 in HCT116 cells was evaluated. In 19 of the 34 methylated genes in HCT116 and in 7 of the 8 methylated genes in KM12SM, the methylation status was downregulated after treatment with $2 \mathrm{mg} / \mathrm{ml}$ of AS2-1 for $24 \mathrm{~h}$. AS2-1 dramatically downregulated the methylation status of p15 and ESRI in HCT116 cells and of MTHFR and $M U C 2$ in KM12SM cells. Both mRNA and protein expression of p15 increased in a dose- and time-dependent manner after treatment with AS2-1. The antineoplaston AS2-1 may normalize the hypermethylation status at the promoter region in various genes including tumor suppressor genes, resulting in activation of the transcription and translation in colon cancer.
\end{abstract}

\section{Introduction}

Antineoplasons are naturally-occurring peptides and amino acid derivatives found in human blood and urine, first described by Burzynski in 1976 (1). Antineoplaston A10 (3-phenylacethyl-amino-2,6-piperidinedione) is the

Correspondence to: Dr Yutaka Ogata, Department of Surgery, Kurume University Medical Center, 155-1 Kokubu-machi, Kurume, 839-0863, Japan

E-mail: yogata@med.kurume-u.ac.jp

Key words: demethylation, epigenetic modification, antineoplaston AS2-1, colon cancer, silencing of tumor suppressor genes first chemically-identified antineoplaston and it is partially hydrolyzed in pancreatic juice to phenylacetylglutamine (PG) and phenylacethyl isoglutamine (isoPG) when administered perorally. PG and isoPG are further metabolized to phenylacetate (PN). The mixture of $P G$ and $P N$ in the ratio of $1: 4$ has been formulated as antineoplaston AS2-1. Antineoplastons have been found to control neoplastic growth. The animal experiment and phase I clinical toxicological studies (2) have demonstrated minimal adverse effects of these agents. Thus, it is postulated that combining these antineoplastons with intensive chemotherapy may increase antitumor efficacy without an increase of adverse effects in cancer patients. Clinical studies have described the antitumor efficacy of antineoplastons for various tumors including hepatocellular carcinoma, colon cancer and glioma (3-5).

Sodium phenylbutyrate (PB) and PN (a metabolite of PB) that is the active ingredient of antineoplaston AS2-1 induce cytostasis, differentiation and apoptosis by several cellular mechanisms, in glioma, neuroblastoma, leukemia cells and adenocarcimoma cells of the breast, colon and lung (6-9). PN activates the $p 53$ and $p 21$ genes through inhibition of methyltransferase and fernesylation of the RAS protein (10). PB activates tumor suppressor genes through inhibition of histone deacetylation $(11,12)$. PG that is also the active ingredient of antineoplaston AS2-1 normalizes the pattern of genome-wide methylation, stabilizing the genes, decreasing expression of oncogenes such as AKT-2 and c-myc (MYCC) and activating tumor suppressors proteins phosphatase and tensin homologue (PTEN) and integrase interactor 1 (INII) and promotes apoptosis (13). Thus, one of the mechanisms underlying the antitumor effect of antineoplaston AS2-1 is considered to involve regulation of tumor suppressor gene expression through demethylation of their promoter sequences and modification (acetylation) of histones.

Epigenetic alterations of gene function are now well known to contribute to the tumorigenesis and cancer progression. Specifically, abnormal promoter region methylation which typically occurs at $\mathrm{CpG}$ islands in known or candidate tumor suppressor genes contributes to tightly heritable gene silencing and can thereby cause the loss of gene function. Silencing of genes is a complex process, which involves methylation of DNA, histone modification and chromatin remodeling. Two biochemical processes play 
a very important part in silencing of the genes: deacetylation of histones and methylation of DNA $(14,15)$. Additional new mechanisms of methylation have been proposed explaining two different issues of DNA methylation in cancer progression: i) site-specific hypermethylation of promoter sequences; and ii) genome-wide hypo-methylation is inducing genomic instability, amplification of oncogenes and silencing of tumor suppressor genes through RNAi mechanism $(16,17)$. Methylation of specific genes or methylation patterns of groups of genes were also found to be associated with responses to chemotherapeutics and prognosis.

The antitumor mechanisms on the epigenetic modification of antineoplastons have not yet been clarified. In the present study, we have investigated the epigenetic modification, in particular in demethylation effect of the antineoplaston AS2-1 and clarify sequential increase of transcription and translation to protein for targeting genes in colon cancer cell lines.

\section{Materials and methods}

Antineoplaston AS2-1. Antineoplaston AS2-1 injected formulation $(20 \mathrm{~g} / 250 \mathrm{ml})$ which is a mixture of PG and PN in the ratio of 1:4, was a kind gift from Dr S.R Burzynski (Burzynski Institute, Houston, TX, USA).

Cell lines and culture. The HCT116 human colon cancer cell line (p53 wild) was obtained from the ATCC (Rockville, MD, USA). The KM12SM human colon cancer cell line ( $p 53$ mutant) was a kind gift from Dr Motowo Nakajima (SBI Arapromo K.K., Tokyo, Japan). Each cell line was cultured in RPMI-1640 medium (Invitrogen, Tokyo, Japan) supplemented with $10 \%$ fetal bovine serum (FBS) at $37^{\circ} \mathrm{C} / 5 \% \mathrm{CO}_{2}$ in $75-\mathrm{cm}^{2}$ culture dishes. The cells were trypsinized once a week with trypsin/EDTA $(0.25 \% / 0.02)$ and the medium was changed twice a week.

In vitro cell growth assay. The HCT116 and KM12SM cells were seeded at a density of $2.5 \times 10^{4}$ into a 6 -well dish containing $4 \mathrm{ml}$ RPMI-1640 medium (Invitrogen, Carlsbad, CA, USA) supplement with $10 \%$ FBS and incubated overnight. The next day, AS2-1 was added to the subconfluent cultures at concentrations of $0.2,0.5,1,2$ and $5 \mathrm{mg} / \mathrm{ml}$. The tumor cells were harvested before AS2-1 treatment as control, and after AS2-1 treatment at 24, 48 and $72 \mathrm{~h}$. The number of viable tumor cells was determined by the trypan blue exclusion test.

Evaluation of methylation profiles at promoter regions by HELP assay (HpaII tiny fragment enrichment by ligationmediated PCR). HpaII-MspI methylation microarray (Methyl-Scan DNA chip; Genomictree Inc, Daejeon, South Korea) was used to investigate the methylation status of 51 kinds of gene promoter region in HCT116 cells and KM12SM cells before and after treatment with $2 \mathrm{mg} / \mathrm{ml}$ of AS2-1 for $24 \mathrm{~h}$. All chemical reagents used were purchased from Sigma-Aldrich (Haverhill, MA, USA) unless otherwise noted. HpaII and MspI restriction enzymes were obtained from New England Biolabs (Ipswich, MA, USA). Oligonucleotides were synthesized by Bioneer Inc. (Daejeon, South Korea).
To avoid incomplete digestion and reduce the background noise signals, $200 \mathrm{ng}$ of genomic DNA was digested with excessive units of HpaII and MspI (80 units each) for $6 \mathrm{~h}$ at $37^{\circ} \mathrm{C}$ with enzyme buffers recommended by the suppliers. The digested samples were inactivated at $65^{\circ} \mathrm{C}$ for $20 \mathrm{~min}$ and then purified with GeneClean Turbo kit (Qbiogene, Irvine, CA, USA) according to the manufacturer's instructions.

Multiplex PCR amplification was done with un-digested and HpaII-, MspI-digested DNA with primers sets to label 51 target promoter regions. The sequences of the gene-specific primer sets used are shown in Table I. During the amplification step, fluorescent dyes were incorporated into the amplicons; Cy3-dUTP in MspI-digested targets, Cy5-dUTP in HpaII-digested targets and undigested samples labeled with Cy5-dUTP by same multiplex PCR. The amplification was carried out according to the general guidelines: denaturating at $94^{\circ} \mathrm{C}$ for $5 \mathrm{~min}$, followed by 30 cycles at $94^{\circ} \mathrm{C}$ for $30 \mathrm{sec}$, at $66^{\circ} \mathrm{C}$ for $45 \mathrm{sec}$, at $72^{\circ} \mathrm{C}$ for $45 \mathrm{sec}$ and a final extension at $72^{\circ} \mathrm{C}$ for $5 \mathrm{~min}$. To assess PCR adequacy and ensure scanning, the human interferon-2 gene without HpaII site was used as a control.

After PCR amplification, all the amplicons were mixed and purified by using QIAquick PCR cleanup kit (Qiagen K.K., Tokyo, Japan). The hybridization mixture (100 $\mu \mathrm{l})$ contained the amplified Cy5 and Cy3-labeled cDNA, 3.5X $\mathrm{SSC}, 5 \mu \mathrm{g}$ of salmon sperm DNA and $0.2 \%$ sodium dodecyl sulfate. It was heated for $2 \mathrm{~min}$ at $95^{\circ} \mathrm{C}$ and immediately applied onto Methyl Scan DNA chip. The arrays were incubated at $65^{\circ} \mathrm{C}$ for $4 \mathrm{~h}$ in an eight-well platform hybridization chamber (Genomictree). To determine the methylation pattern, the hybridized microarray was imaged by an Axon 4000B scanner (Axon Instruments, Inc., Union City, CA, USA). The signal intensities were measured and analyzed by using GenePix Pro (version 4.0) software. If the signal intensity of HpaII amplicon is 2-fold greater than that of MspI amplicon, the target region was considered to be methylated, while $<2$-fold was considered to be unmethylated (minus). Moreover, the methylated status was categorized into 3 degrees, high priority (three plus), middle priority (two plus) and low priority (plus).

Real-time RT-PCR. To clarify the reinforcement of a transcription activity of the methylate normalized gene by AS2-1, real-time RT-PCR (relative quantitative) for p15 messenger RNA in HCT116 cells were evaluated. The HCT116 cells were seeded at a density of $2.5 \times 10^{4} / \mathrm{ml}$ into a 6 -well dish containing $4 \mathrm{ml}$ RPMI-1640 medium (Invitrogen) supplement with $10 \%$ fetal bovine serum (FBS) and incubated overnight. The next day, AS2-1 was added to the subconfluent cultures at concentrations of $0.2,1$ and $2 \mathrm{mg} / \mathrm{ml}$. The tumor cells were harvested before AS2-1 treatment as control, after AS2-1 treatment at 12, 24 and $48 \mathrm{~h}$.

Isolated RNA was controlled for quality by $2 \%$ agarose gel separation and ethidium bromide staining. RNA was quantified by spectrophotometry. Complementary DNA (cDNA) was synthesized using $2 \mu \mathrm{g}$ of total RNA. The $20 \mu \mathrm{l}$ reverse transcription reaction consisted of $2 \mu \mathrm{l} 10 \mathrm{X}$ RT buffer, $0.5 \mathrm{mM}$ each dNTP, $1 \mu \mathrm{M}$ Oligo-dT primers and $4 \mathrm{U}$ Omniscript reverse transcriptase (Qiagen K.K). The reverse transcription reaction was incubated for $1 \mathrm{~h}$ at $37^{\circ} \mathrm{C}$ and then 
Table I. Primer information for HpaII-MspI-PCR assay.

\begin{tabular}{|c|c|c|c|}
\hline Gene & Forward primer $\left(5^{\prime}-3^{\prime}\right)$ & Reverse primer $\left(5^{\prime}-3^{\prime}\right)$ & Amplicon size (bp) \\
\hline ASIC2 & ccaggaggcgaggagagaatg & cetcetctcetcetcetcca & 178 \\
\hline Apaf-1 & ccttggggcttggggtgtgt & cctcaagtcttcgcgggtcg & 201 \\
\hline APC & caggcaacccagacgtccagag & ggaagttgatggcagttgacac & 310 \\
\hline AR & ggacccgactcgcaaactgtt & gctggcgtggtgcgtccet & 195 \\
\hline BRCA1 & gcgtgagctcgctgagacttc & cettcctgatcctcagcgett & 302 \\
\hline hCTR & ggatcagagttggaagagtccc & cetcccagcgccagcgact & 382 \\
\hline CALCR & cctgtgtttacgcggcgcttt & gcagcagaattgatgagagcca & 229 \\
\hline CDH13 & ccatgcaaaacgagggagcgt & cgcacagaacgagcggagttc & 258 \\
\hline CDKN2A (p16) & gcagcatggagccttcggct & ccaggaggaggtctgtgattac & 292 \\
\hline CDKN2B (p15) & ccttggcccagctgaaaacg & gcactctctccttcctaggag & 304 \\
\hline CFTR & cctccagcgttgccaactgg & cgtctgggctcaagctccta & 443 \\
\hline COMT & cccattgctctgtgcagcet & ggctgggtgccttgtctaag & 202 \\
\hline DAPK1 & ccactcactccctagctgtgtt & cccagttgctcgaggcactgc & 224 \\
\hline EDN1 & ggtacacaggccatataggaac & ccgaatccctgggcatcagg & 620 \\
\hline EBR & ggagggaacagcggtttccaa & cgtaacgggaggaatacagac & 284 \\
\hline EPHA3 & cctgtcccatgggcgacg & gctggtgcagagggcagtg & 295 \\
\hline EPO & gcagccccatgacccaca & gctgttatctgcatgtgtgcgt & 175 \\
\hline ESR & cctggatccgtctttcgcgtt & gcagggtgcagaccgtgtcc & 510 \\
\hline FHIT & ctccetccetctgcetttcat & ggcgatccaccetgagacc & 217 \\
\hline H19 & gccatgtgcaaagtatgtgcag & cctggacagttccagcacac & 228 \\
\hline Heparanase & gggagaggaagggatgaatact & ggtcacgttcacttacgaaatca & 273 \\
\hline hMLH1 & cgggcagtacctctctcagcaac & ggcttgtgtgcctctgctgagg & 528 \\
\hline HTR1B & gggagcttccttggccagga & ctctgecetccetctcttttc & 434 \\
\hline IL-8 & ggaagtgtgatgactcaggttt & ggctcttgtcctagaagcttgt & 195 \\
\hline JunB & ggaaacgacgccaggaaagct & gcagcgagcggcgagctct & 174 \\
\hline LAMA5 & ggcacaggctgactcatgtgt & gcttgcaggctgaccgcct & 192 \\
\hline LDHB & gggagtgtgcacacttgagc & ctaccaggagagagaaggctc & 237 \\
\hline BLT1 & gtgagcgccatcgtgcttgc & caccactttcagctgagggg & 332 \\
\hline LRP2 & cgtgtgcacgtgtgagtgtg & cetctgctagcgaacgetcc & 485 \\
\hline MAGE1 & gcagagagagagtcttggctttc & cttgactgccgaccagtcctg & 501 \\
\hline MDR3 & cctaggagtactcacttcagg & cetctgcttctttgagcttgg & 230 \\
\hline MGMT & ccgtttgcgacttggtgagt & ggaaaggctgggcaacacctg & 199 \\
\hline MTHFR & gctgcctgccecetgatgc & ccccaggcaccaccactcc & 346 \\
\hline MUC2 & ggttggtcctcccagcgtaa & cctggcaggagggtaggag & 239 \\
\hline PGR & ggtagggaggggctttggg & ccagcgagcggcaagtggg & 579 \\
\hline PIK3CG & ccetctggggcattcattacta & ggaagcactacagccettcag & 139 \\
\hline PLS3 (TLS3) & cacccagttgatgtgacaggc & gctccaactgaaatttctccga & 393 \\
\hline PTGS2 & cccatccaaggcgatcagtc & ggtaggctttgctgtctgagg & 471 \\
\hline RAR-b & gtgacagaagtagtaggaagtga & ccaggcttgctcggccaatc & 338 \\
\hline $\mathrm{RB} 1$ & ggatagggatgaggcccaca & cgtcccctgagaaaa accgg & 341 \\
\hline $\mathrm{S} 100 \mathrm{~A} 2$ & ccacagttctctcattccagc & ctcaggattctttttgcagcaac & 578 \\
\hline SHP1 & gctctgcttctcttccettgc & gggactaagcctcagatgcag & 193 \\
\hline SKT11 (LKB1) & cgaggacgaagttgaccetg & ggacccagggtcctggagt & 324 \\
\hline NIS & cccagtccagggctgaaagg & ctccetgggttaggaatctatg & 468 \\
\hline HLTF & ggagacggcgtcgacgtct & cgctgagtgggatgacaagag & 181 \\
\hline SRBC & gcagtggagacctgaaacagg & ctggctgcactacggtcagg & 286 \\
\hline TFF1 & ctcagatccctcagccaagata & cgagtcagggatgagaggcc & 229 \\
\hline TP73 & gcctttggcgccaaagacagc & cgaaaccgcttagtaaccaactc & 308 \\
\hline TUSC3 (N33) & ccttcatcatccaagaaggcatt & cgaggacgcagagtaggaga & 295 \\
\hline VHL & cgagttggcctagcctcgc & cgtcttcttcagggccgtac & 311 \\
\hline WT1 & gctgctgagtgaatggagcg & gggtgaatgagtaggtgggag & 293 \\
\hline IFN (control) & gcagctgcagcagttccaga & tgctcatgagttttccetggt & 221 \\
\hline
\end{tabular}



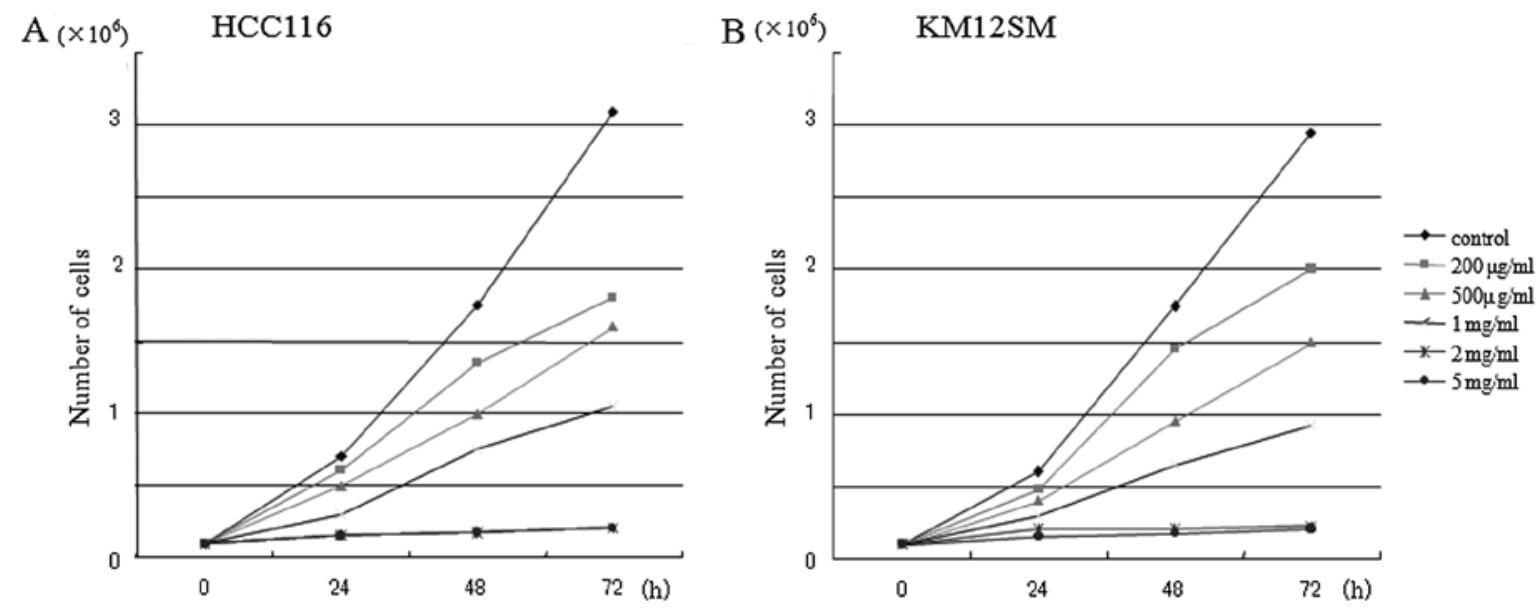

Figure 1. In vitro cell growth inhibition by antineoplaston AS2-1. Human colon carcinoma HCT116 and KM12SM cells were incubated as described in Materials and methods. Antineoplaston AS2-1 inhibited (A) HCT116 and (B) KM12SM cell growth in a time- and dose-dependent manner.

Table II. Methylation status in HCT116 cells before and after treatment with AS2-1.

\begin{tabular}{|c|c|c|c|c|c|c|}
\hline $\begin{array}{l}\text { Apaf-1 } \\
(+) \Rightarrow(-)\end{array}$ & $\begin{array}{c}\text { APC } \\
(+) \Rightarrow(-)\end{array}$ & $\begin{array}{c}\text { AR } \\
(+) \Rightarrow(-)\end{array}$ & $\begin{array}{l}\text { ASIC2 } \\
(-) \Rightarrow(-)\end{array}$ & $\begin{array}{c}\text { BLT1 } \\
(+++) \Rightarrow(+++)\end{array}$ & $\begin{array}{l}\text { BRCA1 } \\
(-) \Rightarrow(-)\end{array}$ & $\begin{array}{l}\text { CALCA } \\
(-) \Rightarrow(-)\end{array}$ \\
\hline $\begin{array}{l}\text { CDH13 } \\
(+) \Rightarrow(+)\end{array}$ & $\begin{array}{c}\text { CFTR } \\
(-) \Rightarrow(-)\end{array}$ & $\begin{array}{l}\text { COMT } \\
(-) \Rightarrow(-)\end{array}$ & $\begin{array}{c}\text { DAPK } \\
(+) \Rightarrow(+)\end{array}$ & $\begin{array}{c}\text { EBR } \\
(+) \Rightarrow(-)\end{array}$ & $\begin{array}{c}\text { EDN1 } \\
(-) \Rightarrow(-)\end{array}$ & $\begin{array}{l}\text { EphA3 } \\
(-) \Rightarrow(-)\end{array}$ \\
\hline $\begin{array}{l}\text { EPO } \\
(+) \Rightarrow(-)\end{array}$ & $\begin{array}{c}\text { ESR1 } \\
(++) \Rightarrow(-)\end{array}$ & $\begin{array}{c}\text { FHIT } \\
(+) \Rightarrow(-)\end{array}$ & $\begin{array}{c}\mathrm{hCTR} \\
(+) \Rightarrow(+)\end{array}$ & $\begin{array}{l}\text { Heparanase } \\
(+) \Rightarrow(+)\end{array}$ & $\begin{array}{c}\text { HLTF } \\
(-) \Rightarrow(-)\end{array}$ & $\begin{array}{l}\text { hMLH1 } \\
(+) \Rightarrow(-)\end{array}$ \\
\hline $\begin{array}{l}\text { HTR1B } \\
(+) \Rightarrow(-)\end{array}$ & $\begin{array}{c}\text { H19 } \\
(+) \Rightarrow(+)\end{array}$ & $\begin{array}{c}\text { IL-8 } \\
(-) \Rightarrow(-)\end{array}$ & $\begin{array}{c}\text { JunB } \\
(+) \Rightarrow(+)\end{array}$ & $\begin{array}{l}\text { Laminin5 } \\
(-) \Rightarrow(-)\end{array}$ & $\begin{array}{c}\text { LDHB } \\
(+) \Rightarrow(-)\end{array}$ & $\begin{array}{c}\text { LKB } \\
(+) \Rightarrow(-)\end{array}$ \\
\hline $\begin{array}{l}\text { LRP2 } \\
(+) \Rightarrow(-)\end{array}$ & $\begin{array}{l}\text { MAGE } \\
(+) \Rightarrow(-)\end{array}$ & $\begin{array}{c}\text { MDR3 } \\
(-) \Rightarrow(-)\end{array}$ & $\begin{array}{l}\text { MGMT } \\
(-) \Rightarrow(-)\end{array}$ & $\begin{array}{c}\text { MTHFR } \\
(++) \Rightarrow(++)\end{array}$ & $\begin{array}{c}\text { MUC2 } \\
(++) \Rightarrow(+)\end{array}$ & $\begin{array}{c}\text { NIS } \\
(+) \Rightarrow(+)\end{array}$ \\
\hline $\begin{array}{l}\text { N33 } \\
(+) \Rightarrow(-)\end{array}$ & $\begin{array}{c}\text { PGR } \\
(-) \Rightarrow(-)\end{array}$ & $\begin{array}{l}\text { PIK3CG } \\
(-) \Rightarrow(-)\end{array}$ & $\begin{array}{l}\text { PTGS2 } \\
(-) \Rightarrow(-)\end{array}$ & $\begin{array}{c}\text { P15 } \\
(++) \Rightarrow(-)\end{array}$ & $\begin{array}{c}\text { P16 } \\
(-) \Rightarrow(-)\end{array}$ & $\begin{array}{c}\text { P73 } \\
(+) \Rightarrow(+)\end{array}$ \\
\hline $\begin{array}{l}\text { RAR- } \beta \\
(+) \Rightarrow(-)\end{array}$ & $\begin{array}{c}\text { RB1 } \\
(+) \Rightarrow(+)\end{array}$ & $\begin{array}{c}\text { SHP1 } \\
(+) \Rightarrow(-)\end{array}$ & $\begin{array}{c}\text { SRBC } \\
(+) \Rightarrow(-)\end{array}$ & $\begin{array}{l}\mathrm{S} 100 \mathrm{~A} 2 \\
(+) \Rightarrow(-)\end{array}$ & $\begin{array}{c}\text { TFF1 } \\
(-) \Rightarrow(-)\end{array}$ & $\begin{array}{c}\text { TLS3 } \\
(+) \Rightarrow(+)\end{array}$ \\
\hline $\begin{array}{l}\text { VHL } \\
(+) \Rightarrow(+)\end{array}$ & $\begin{array}{c}\text { WT1 } \\
(+) \Rightarrow(+)\end{array}$ & & & & & \\
\hline
\end{tabular}

at $93^{\circ} \mathrm{C}$ for $15 \mathrm{~min}$. Real-time PCR analysis was performed using the ABI Prism 7700 sequence detection system (Applied Biosystems, Foster City, CA, USA) as previously described (18). Briefly, reactions were performed in a 96-well optical reaction plated on cDNA equivalent to $50 \mathrm{ng}$ of DNasedigested RNA in a volume of $25 \mu 1$, containing $12.5 \mu \mathrm{l}$ of TaqMan Universal Master Mix and optimized concentrations of carboxy fluorescein (FAM)-labeled probe and forward and reverse primers following the manufacturer's protocol. All primers and FAM-labeled probes for mouse $p 15$ (forward,
5'-TCTGCAGCTGGATCTGGTCC-3' and reverse, 5'-TCCT GAAAGGTAGAGGGCCC-3') and $G A P D H$ (forward, 5'-CA TCTCCTCCCGTTCTGCC-3' and reverse, 5'-GTGGTGC AGGATGCATTGC-3') were obtained from Applied Biosystems. The mRNA expression of $p 15$ was normalized to the level of GAPDH mRNA. Data were processed by the RQ Manager 1.2 software.

Western blot analysis. The cells were cultured as previously described. The cells were directly lysed in a sample 
buffer (0.5 M Tris-HCl, pH 6.8, $10 \%$ glycerol, $10 \%$ SDS, $6 \%$ mercaptoethanol, $0.05 \%$ bromophenol blue). Protein $(10 \mu \mathrm{g})$ was separated on $4 \%$ SDS-PAGE gel at $120 \mathrm{~V}$ for $1.5 \mathrm{~h}$. After electrophoresis, the proteins were transferred to a PVDF membrane (Bio-Rad Laboratories, Hercules, $\mathrm{CA}, \mathrm{USA})$ at $100 \mathrm{~V}$ for $60 \mathrm{~min}$. The membrane was blocked in PBS containing $0.1 \%$ Tween-20 (FBS-Tween) with 5\% skimmed milk at room temperature for $60 \mathrm{~min}$, subsequently incubated with anti-p15 mouse monoclonal antibody (Abcam, Cambridge, UK) at $4^{\circ} \mathrm{C}$ overnight. After washing with PBS-Tween, the membrane was incubated with a horseradish peroxidase-conjugated goat anti-rabbit IgG or anti-mouse IgG secondary antibody (Santa Cruz Biotechnology, Dallas, TX, USA). The membrane was washed with PBS-Tween, and the signal was detected using an ECL detection kit (Amersham Pharmacia Biotech Inc., Piscataway, NJ, USA). A mouse monoclonal antibody against $\beta$-actin (Sigma-Aldrich, St. Louis, MO, USA) was used to control for protein loading. The amount of each protein was quantified as ratio to actin. Quantification of band densities was performed using the public domain NIH Image software.

\section{Results}

Cell growth inhibition by antineoplaston AS2-1. Antineoplaston AS2-1 inhibited the cell growth of KM12SM and HCT116 in a culture in a dosa- and time-dependent manner (Fig. 1). There was no difference in cell growth inhibition by AS2-1 between the wild p53 HCT116 and the mutant $p 53$ KM12SM cell lines.
Table III. Summary of methylation status in HCT116 cells.

\begin{tabular}{|c|c|c|c|c|}
\hline \multicolumn{2}{|c|}{ Before treatment } & \multicolumn{2}{|c|}{ After treatment } & \multirow[b]{2}{*}{$(\%$} \\
\hline Status & $\mathrm{n}$ & Status & $\mathrm{n}$ & \\
\hline$(-)$ & 17 & $(-)$ & 17 & 100 \\
\hline \multirow[t]{2}{*}{$(+)$} & 29 & $(+)$ & 13 & 45 \\
\hline & & $(-)$ & 16 & 55 \\
\hline \multirow[t]{3}{*}{$(++)$} & 4 & $(++)$ & 1 & 25 \\
\hline & & $(+)$ & 1 & 25 \\
\hline & & $(-)$ & 2 & 50 \\
\hline$(+++)$ & 1 & $(+++)$ & 1 & 100 \\
\hline
\end{tabular}

Methylation status. Among the 51 genes, there were 34 methylated genes in promoter sequence in HCT116 cells. In $19(56 \%)$ of the 34 methylated genes the methylation status was downregulated after treatment with $2 \mathrm{mg} / \mathrm{ml}$ of AS2-1 for $24 \mathrm{~h}$, in particular, the methylation status of cyclin-dependent kinase inhibitor p15 (INK4B) and estrogen receptor 1 (ESRI) in HCT116 cells were dramatically downregulated from two plus to minus (Tables II and III). Among the 51 genes, there were 8 methylated genes in KM12SM cells. In 7 (88\%) of the 8 methylated genes in KM12SM cells, the methylation status was downregulated after treatment with $2 \mathrm{mg} / \mathrm{ml}$ of AS2-1 for $24 \mathrm{~h}$, in particular the methylation status of methylenetetrahydrofolate reductase $(M T H F R)$ and mucin2 (MUC2) in KM12SM cells was dramatically downregulated from

Table IV. Methylation status in KM12SM cells before and after treatment with AS2-1.

\begin{tabular}{|c|c|c|c|c|c|c|}
\hline $\begin{array}{l}\text { Apaf-1 } \\
(-) \Rightarrow(-)\end{array}$ & $\begin{array}{c}\text { APC } \\
(-) \Rightarrow(-)\end{array}$ & $\begin{array}{c}\text { AR } \\
(-) \Rightarrow(-)\end{array}$ & $\begin{array}{l}\text { ASIC2 } \\
(-) \Rightarrow(-)\end{array}$ & $\begin{array}{c}\text { BLT1 } \\
(+++) \Rightarrow(+++)\end{array}$ & $\begin{array}{l}\text { BRCA1 } \\
(-) \Rightarrow(-)\end{array}$ & $\begin{array}{l}\text { CALCA } \\
(-) \Rightarrow(-)\end{array}$ \\
\hline $\begin{array}{l}\text { CDH13 } \\
(+) \Rightarrow(-)\end{array}$ & $\begin{array}{c}\text { CFTR } \\
(-) \Rightarrow(-)\end{array}$ & $\begin{array}{c}\text { COMT } \\
(-) \Rightarrow(-)\end{array}$ & $\begin{array}{c}\text { DAPK } \\
(-) \Rightarrow(-)\end{array}$ & $\begin{array}{c}\text { EBR } \\
(-) \Rightarrow(-)\end{array}$ & $\begin{array}{c}\text { EDN1 } \\
(-) \Rightarrow(-)\end{array}$ & $\begin{array}{c}\text { EphA3 } \\
(-) \Rightarrow(-)\end{array}$ \\
\hline $\begin{array}{l}\text { EPO } \\
(-) \Rightarrow(-)\end{array}$ & $\begin{array}{c}\text { ESR1 } \\
(-) \Rightarrow(-)\end{array}$ & $\begin{array}{c}\text { FHIT } \\
(-) \Rightarrow(-)\end{array}$ & $\begin{array}{c}\text { hCTR } \\
(+) \Rightarrow(-)\end{array}$ & $\begin{array}{l}\text { Heparanase } \\
\qquad(-) \Rightarrow(-)\end{array}$ & $\begin{array}{c}\text { HLTF } \\
(-) \Rightarrow(-)\end{array}$ & $\begin{array}{l}\text { hMLH1 } \\
(-) \Rightarrow(-)\end{array}$ \\
\hline $\begin{array}{l}\text { HTR1B } \\
(-) \Rightarrow(-)\end{array}$ & $\begin{array}{c}\text { H19 } \\
(+) \Rightarrow(-)\end{array}$ & $\begin{array}{c}\mathrm{IL}-8 \\
(-) \Rightarrow(-)\end{array}$ & $\begin{array}{c}\text { JunB } \\
(-) \Rightarrow(-)\end{array}$ & $\begin{array}{l}\text { Laminin5 } \\
(-) \Rightarrow(-)\end{array}$ & $\begin{array}{l}\text { LDHB } \\
(-) \Rightarrow(-)\end{array}$ & $\begin{array}{c}\text { LKB } \\
(-) \Rightarrow(-)\end{array}$ \\
\hline $\begin{array}{l}\text { LRP2 } \\
(-) \Rightarrow(-)\end{array}$ & $\begin{array}{l}\text { MAGE } \\
(-) \Rightarrow(-)\end{array}$ & $\begin{array}{l}\text { MDR3 } \\
(-) \Rightarrow(-)\end{array}$ & $\begin{array}{l}\text { MGMT } \\
(-) \Rightarrow(-)\end{array}$ & $\begin{array}{c}\text { MTHFR } \\
(++) \Rightarrow(-)\end{array}$ & $\begin{array}{c}\text { MUC2 } \\
(++) \Rightarrow(-)\end{array}$ & $\begin{array}{c}\text { NIS } \\
(-) \Rightarrow(-)\end{array}$ \\
\hline $\begin{array}{l}\text { N33 } \\
(-) \Rightarrow(-)\end{array}$ & $\begin{array}{c}\text { PGR } \\
(-) \Rightarrow(-)\end{array}$ & $\begin{array}{l}\text { PIK3CG } \\
(-) \Rightarrow(-)\end{array}$ & $\begin{array}{l}\text { PTGS2 } \\
(-) \Rightarrow(-)\end{array}$ & $\begin{array}{c}\text { P15 } \\
(-) \Rightarrow(-)\end{array}$ & $\begin{array}{c}\text { P16 } \\
(-) \Rightarrow(-)\end{array}$ & $\begin{array}{c}\text { P73 } \\
(-) \Rightarrow(-)\end{array}$ \\
\hline $\begin{array}{l}\text { RAR- } \beta \\
(-) \Rightarrow(-)\end{array}$ & $\begin{array}{c}\text { RB1 } \\
(+) \Rightarrow(-)\end{array}$ & $\begin{array}{c}\text { SHP1 } \\
(-) \Rightarrow(-)\end{array}$ & $\begin{array}{l}\text { SRBC } \\
(-) \Rightarrow(-)\end{array}$ & $\begin{array}{l}\text { S100A2 } \\
(-) \Rightarrow(-)\end{array}$ & $\begin{array}{c}\text { TFF1 } \\
(-) \Rightarrow(-)\end{array}$ & $\begin{array}{c}\text { TLS3 } \\
(-) \Rightarrow(-)\end{array}$ \\
\hline $\begin{array}{l}\text { VHL } \\
(-) \Rightarrow(-)\end{array}$ & $\begin{array}{c}\text { WT1 } \\
(+) \Rightarrow(-)\end{array}$ & & & & & \\
\hline
\end{tabular}


Table V. Summary of methylation status in KM12SM cells.

\begin{tabular}{|c|c|c|c|c|}
\hline \multicolumn{2}{|c|}{ Before treatment } & \multicolumn{2}{|c|}{ After treatment } & \multirow[b]{2}{*}{$(\%)$} \\
\hline Status & $\mathrm{n}$ & Status & $\mathrm{n}$ & \\
\hline$(-)$ & 43 & $(-)$ & 43 & 100 \\
\hline \multirow[t]{2}{*}{$(+)$} & 5 & $(+)$ & 0 & \\
\hline & & $(-)$ & 5 & 100 \\
\hline \multirow[t]{3}{*}{$(++)$} & 2 & $(++)$ & 0 & \\
\hline & & $(+)$ & 0 & \\
\hline & & $(-)$ & 2 & 100 \\
\hline$(+++)$ & 1 & $(+++)$ & 1 & 100 \\
\hline
\end{tabular}

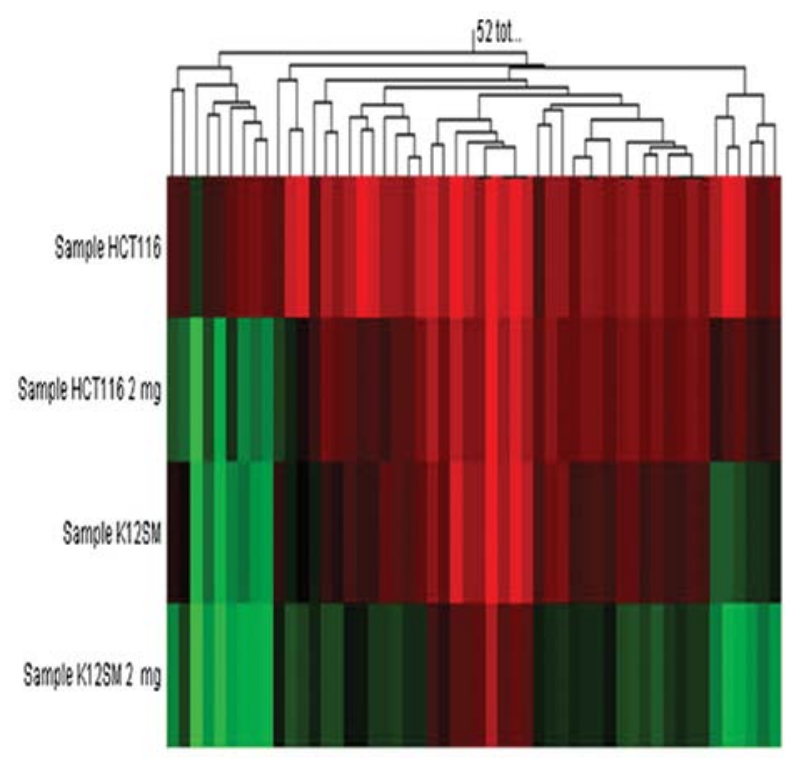

Figure 2. Multiple clustering analysis of methylation status. Red pixels represent methylation status: the intensities of red pixels depend on methylation status (priority). Greenish black pixels represent unmethylated status. Sample HCT116, before treatment; sample HCT116 $2 \mathrm{mg}$, after treatment with $2 \mathrm{mg}$ of antineoplaston AS2-1 for $24 \mathrm{~h}$; sample KM12SM, before treatment; sample KM12SM $2 \mathrm{mg}$, after treatment with $2 \mathrm{mg}$ of AS2-1 for $24 \mathrm{~h}$
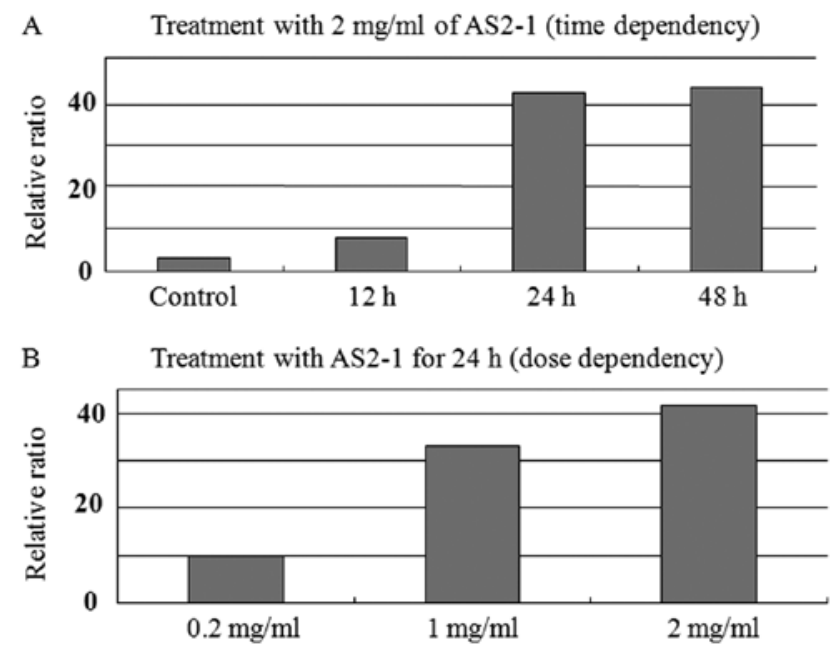

Figure 3. Real-time RT-PCR analysis for p15 mRNA in HCT116 cells. (A) HCT116 cells were treated with $2 \mathrm{mg} / \mathrm{ml}$ of antineoplaston AS2-1 for 12 , 24 and $48 \mathrm{~h}$. (B) HCT116 cells were treated with $0.2,1$ and $2 \mathrm{mg} / \mathrm{ml}$ of AS2-1 for $24 \mathrm{~h}$. AS2-1 upregulated the expression of $p 15$ mRNA in a time- and dose-dependent manner in HCT116 cells.
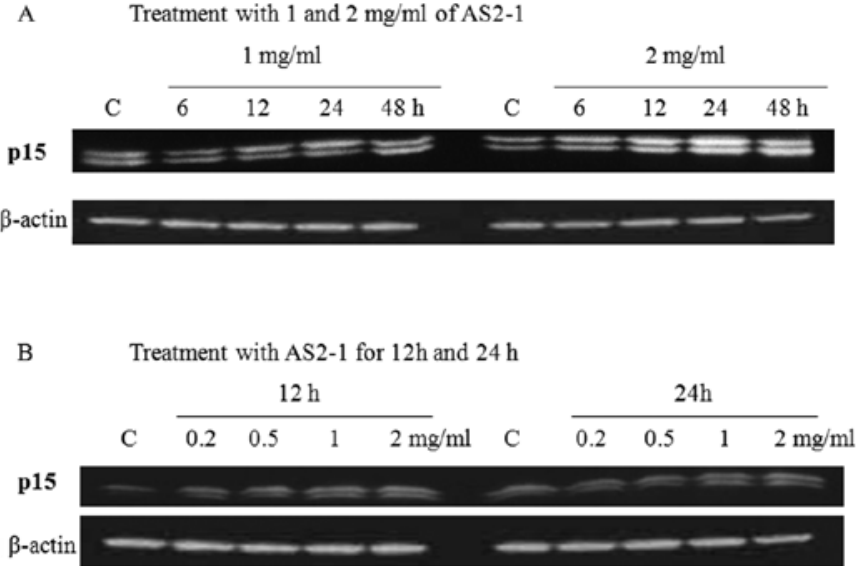

Figure 4. Western blot analysis for p15 protein in HCT116 cells. (A) HCT116 cells were treated with $1 \mathrm{mg} / \mathrm{ml}$ or $2 \mathrm{mg} / \mathrm{ml}$ of antineoplaston AS2-1 for up to $48 \mathrm{~h}$. (B) HCT116 cells were treated with $0.2,0.5,1$ and $2 \mathrm{mg} / \mathrm{ml}$ of AS2-1 for 12 or $24 \mathrm{~h}$. AS2-1 upregulated the expression of $\mathrm{p} 15$ protein in a time- and dose-dependent manner in HCT116 cells.

two plus to minus (Tables IV and V). There was no gene with methylation status upregulated in both HCT116 and KM12SM cells.

Of interest, in between the cell lines there was a difference in demethylation effect of AS2-1 in the 8 genes which were methylated in both HCT116 cells and KM12SM cells. Among the 8 genes, there was only one gene (MUC2) of which methylation status was downregulated after treatment with AS2-1 in HCT116 cells, whereas in 7 of the 8 methylated genes in KM12SM cells, the methylation status were downregulated by AS2-1 (Fig. 2).

Transcription of p15 mRNA. Real-time RT-PCR analysis revealed that AS2-1 upregulated the expression of $p 15$ mRNA in a time- and dose-dependent manner in HCT116 cells (Fig. 3).

Translation of p15 protein. Western blot analysis revealed that AS2-1 upregulated the expression of $\mathrm{p} 15$ protein in a time- and dose-dependent manner in HCT116 cells (Fig. 4).

\section{Discussion}

Burzynski found compounds in the blood and urine of healthy adults that were absent in blood and urine of cancer patients, as first described in 1976 (1). He proposed the hypothesis that these peptide fractions could trigger normal differentiation and apoptosis in neoplastic cells and their deficiency in cancer patients contributed to disease progression. These peptide fractions were termed 'antineoplastons'.

Re-expression of abnormally silenced suppressor genes is being investigated for potential clinical applications. Based on animal experiments and human observations, the drugs which can restore normal gene expression in aging should inhibit insulin-like growth factor 1 (IGF-1)/AKT and RAS pathways and provide proper anticancer defense through normal activity of tumor suppressors $p 53$ and $p 21$ (19). It has also been introduced that a group of amino acid deriva- 
tives and organic acids activate the tumor suppressors $p 53$, $p 21, P T E N$ and INII and decrease overexpression of $R A S$ and $A K T-2$ and $M Y C C$ oncogenes (20).

The current theory of the mechanisms of action of antineoplastons is that they function as 'molecular switches', turning on tumor suppressor genes and turning off oncogenes. It has been suggested that AS2-1 and PN activate tumor suppressor genes $p 53$ and $p 21$ through demethylation of their promoter sequences (21). In the present study, the methylation chip analyses revealed that AS2-1 downregulated methylation status at promoter sequences in various genes including well-known tumor suppressor genes and the candidates for tumor suppressor gene in both p53 wild HCT116 and p53 mutant KM12SM colon cancer cells. The results suggest that AS2-1 has a potent effect to normalize hypermethylation at promoter regions independently of $p 53$ mutation. Of interest, the demethylation effect was seen more completely in the KM12SM cells (8 methylated genes) than in the HCT116 cells (34 methylated genes). The difference in demethylation effect in the same genes between the two cell lines suggests that the demethylation effect of AS2-1 may depend on the cell type not on the genes. Cytidine analogs such as 5-azacytidine (azacitidine) and 5-azadeoxycytidine (decitabine) are the most commonly used demethylating agents. These compounds work by binding to DNA methyltransferases that catalyse the methylation reaction and titrate out DNA methyltransferases (22). If the demethylation effect of AS2-1 depends on activity of DNA methyltransferases, it is suspected that AS2-1 may demethylate at $\mathrm{CpG}$ islands of promoter region more completely in tumor cells with a low DNA methyltransferase activity.

One of the dramatically demethylated genes after treatment with AS2-1 in HCT116 cells was the tumor suppressor gene, cyclin-dependent kinase inhibitor p15 (INK4B). Sequentially the expression of $15 \mathrm{mRNA}$ and 15 protein was upregulated by treatment with AS2-1. The results indicate that treatment with AS2-1 leads to re-expression of p15 mRNA and p15 protein. This gene is localized to a region on chromosome 9p21 frequently deleted in human tumors. $p 15$ gene is an important mediator of cell cycle control, especially in pathways stimulated by TGF- $\beta$ (23), raising the issue of whether inactivation of one or both of the genes and cyclin-dependent kinase inhibitor pl6 (INK4A) with homozygous deletion involving the nearby $p 15$ is necessary, because both proteins are inhibitors of cyclin-dependent kinase 4 (INK4 family) $(24,25)$ and are highly homologous throughout their coding sequence (26). It has been reported that the $p 15$ gene is commonly inactivated in association with promoter region hypermethylation involving multiple sites in a 5'-CpG island in glioma, leukemia and myelodysplastic symdromes. In other tumors, including lung, head and neck, breast, prostate and colon cancer, inactivation of p15 occurs rarely and with concomitant inactivation of p16. It has been shown that aberrant methylation of p15 is associated with transcriptional loss of this gene and treatment with the demethylating agent decitabine leads to reactivation of p15, inducing growth arrest and apoptosis in myeloid cell lines (27). AS2-1 may activate silenced tumor suppressor $p 15$ by demethylation and sequentially upregulates the expression of p15 protein in colon cancer HCT116 cells.
In conclusion, antineoplaston AS2-1 may normalize hypermethylation status at the promoter region in various tumor suppressor genes of which expression is silenced in colon cancer. Then, AS2-1 activates the gene transcription and protein translation, resulting in differentiation, cell cycle arrest and apoptosis in cancer cells.

\section{Acknowledgements}

The present study was supported by a grant-in-aid for Scientific Research (C) (no. 13671364) and a grant-in-aid for Young Scientist (B) (no. 14770672) from the Ministry of Education, Culture, Sports, Science and Technology of Japan.

\section{References}

1. Burzynski SR: Antineoplastons: biochemical defense against cancer. Physiol Chem Phys 8: 275-279, 1976.

2. Tsuda H, Hara H, Eriguchi N, Nishida H, Yoshida H, Kumabe T and Sugita Y: Toxicological study on antineoplaston A-10 and AS2-1 in cancer patients. Kurume Med J 42: 241-246, 1996.

3. Tsuda H, Sata M, Kumabe T, Uchida M and Hara H: The preventive effect of antineoplaston AS2-1 on HCC recurrence. Oncol Rep 10: 391-397, 2003.

4. Ogata Y, Tsuda H, Matono K, Kumabe T, Saitsu H, Hara H, Akagi Y, Araki Y, Sata M and Shirouzu K: Long-term survival following treatment with antineoplastons for colon cancer with unresectable multiple liver metastasis: report of a case. Surg Today 33: 448-453, 2003.

5. Burzynski SR, Weaver RA, Lewy RI, Janicki TJ, Jurida GF, Szymkowski BG, Khan MI and Bestak M: Phase II study of antineoplaston A10 and AS2-1 in children with recurrent and progressive multicentric glioma. a preliminary report. Drugs $\mathrm{R}$ D 5: 315-326, 2004.

6. Liau MC, Lee SS and Burzynski SR: Hypomethylation of nucleic acids: a key to the induction of terminal differentiation. Int J Exp Clin Chemother 2: 187-199, 1989.

7. Samid D, Shack S and Myers CE: Selective growth arrest and phenotypic reversion of prostate cancer cells in vitro by nontoxic pharmacological concentrations of phenylacetate. J Clin Invest 91: 2288-2295, 1993.

8. Liu L, Shack S, Stetler-Stevenson WG, Hudgins WR and Samid D: Differentiation of cultured human melanoma cells induced by the aromatic fatty asid phenylacetete and phenylbutyrate. J invest Dermatol 103: 335-340, 1994.

9. Melchior SW, Brown LG, Figg WD, Quinn JE, Santucci RA, Brunner J, Thüroff JW, Lange PH and Vessella RL: Effect of phenylbutyrate on proliferation and apotosis in human prostate cancer cells in vitro and in vivo. Int J Oncol 14: 501-508, 1999.

10. Shack S, Chen LC, Miller AC, Danesi R and Samid D: Increased susceptibility of ras-transformed cells to phenylacetate is associated with inhibition of p21ras isoprenylation and phenotypic reversion. Int J Cancer 63: 124-129, 1995.

11. Yu KH, Weng LJ, Fu S and Gore SD: Augmentation of phenylbutyrate-induced differentiation of myeloid leukemia cells using all-trans retinoic acid. Leukemia 13: 1258-1265, 1999.

12. Marks PA, Richon VM and Rifkind RA: Histone deacetylase inhibitors: inducers of differentiation or apoptosis of transformed cells. J Natl Cancer Inst 92: 1210-1216, 2000.

13. Waldbillig R and Burzynski SR: Mechanism of action, uptake, and gene array studies on the antineoplastic agent phenylacetylglutamine (PG) in human glioma cells U-87. Neuro Oncol 5: 309, 2003.

14. Goldberg AD, Allis CD and Bernstein E: Epigenetics: a landscape takes shape. Cell 128: 635-638, 2007.

15. Bernstein BE, Meissner A and Lander ES: The mammalian epigenome. Cell 128: 669-681, 2007.

16. Sieber OM, Heinimann K and Tomlinson IP: Genomic instability - the engine of tumorigenesis? Nat Rev Cancer 3: 701-708, 2003.

17. Schramke V and Allshire R: Hairpin RNAs and retrotransposon LTRs effect RNAi and chromatin-based gene silencing. Science 301: 1069-1074, 2003. 
18. Pickett MA, Everson JS, Pead PJ and Clarke IN: The plasmids of Chlamydia trachomatis and Chlamydophila pneumoniae (N16) accurate determination of copy number and the paradoxical effect of plasmid-curing agents. Microbiology 151: 893-903, 2005.

19. Vousden KH and Lu X: Live or let die: the cell's response to p53. Nat Rev Cancer 2: 594-604, 2002.

20. Burzynski SR: The present state of antineoplaston research (1). Integr Cancer Ther 3: 47-58, 2004.

21. Burzynski SR: Aging: gene silencing or gene activation? Med Hypotheses 64: 201-208, 2005.

22. Holliday R and Ho T: DNA methylation and epigenetic inheritance. Methods 27: 179-183, 2002.

23. Hannon GJ and Beach D: p15 $5^{\mathrm{INK} 4 \mathrm{~B}}$ is a potential effector of TGF- $\beta$-induced cell cycle arrest. Nature 371: 257-261, 1994.
24. Serrano M, Hannon GJ and Beach D: A new regulatory motif in cell-cycle control causing specific inhibition of cyclin D/CDK4. Nature 366: 704-707, 1993.

25. Jen J, Harper W, Bigner S H, Bigner DD, Papadopoulos N, Markowitz S, Willson JKV, Kinzler KW and Vogelstein B: Deletion of p16 and p15 genes in brain tumors. Cancer Res 54: 6353-6358, 1994.

26. Kamb A, Gruis NA, Weaver-Feldhaus J, Lie Q, Harshman K, Tavtingian SV, Stockert E, Day RS, Johnson BE and Skolnick MH: A cell cycle regulator potentially involved in genesis of many tumor types. Science 264: 436-440, 1994.

27. Berg T, Guo Y, Abdelkarim M, Fliegauf $M$ and Lübbert M: Reversal of p15/INK4b hypermethylation in AML1/ ETO-positive and -negative myeloid leukemia cell lines. Leuk Res 31: 497-506, 2007. 